\title{
Case series on multiple prostate re-irradiation for locally recurrent prostate cancer: something ventured, something gained
}

\author{
S. VOLPE ${ }^{1,2, *}$, B. A. JERECZEK-FOSSA ${ }^{1,2, *}$, D. ZERINI ${ }^{1}$, D. P. ROJAS ${ }^{1,2}$, C. FODOR ${ }^{1}$, A. VAVASSORI ${ }^{1}$, P. ROMANELLI ${ }^{1}$, S. VIGORITO $^{3}$, E. RONDI ${ }^{3}$,

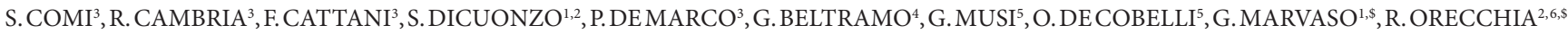

${ }^{1}$ Department of Radiotherapy, European Institute of Oncology, Milan, Italy; ${ }^{2}$ Department of Oncology and Hemato-oncology, University of Milan, Milan, Italy; ${ }^{3}$ Department of Medical Physics, European Institute of Oncology, Milan Italy; ${ }^{4}$ CyberKnife Center CDI, Milan, Italy; ${ }^{5}$ epartment of Urology, European Institute of Oncology, Milan, Italy; ${ }^{6}$ Scientific Directorate, European Institute of Oncology, Milan, Italy

${ }^{*}$ Correspondence: stefania.volpe@ieo.it

"Contributed equally to this work.

${ }^{\$}$ These authors share senior authorship.

Received July 23, 2018 / Accepted October 17, 2018

\begin{abstract}
The aim is to present the technical feasibility and efficacy of multiple re-irradiation (re-EBRT) for local recurrence of prostate cancer $(\mathrm{PCa})$ using retrospective analysis of an updated series of patients who received ablative re-EBRT with stereotactic image-guided technique for isolated local recurrence of PCa. Eight patients received three RT courses (2 re-RTs); of those 2 received 4 RT courses ( 3 re-RTs). Local relapse in the prostate was assessed by multiparametric magnetic resonance and/ or choline positron emission tomography. Before treatment planning, all patients had been evaluated for late toxicity from previous RT according to RTOG/EORTC. Biochemical control was assessed according to Phoenix definition. Mean age at the third RT course was 68 (standard deviation, SD: 7.2); all patients had a good performance status. At diagnosis, four cases were classified as high risk PCa, three as intermediate and one as low per NCCN 2017. Biochemical progression free interval after first and second RT-course were 74 (IQR: 59.3-133.6) months and 33 (IQR: 20.8-53.1) months, respectively. Biochemical and radiological response was registered in all patients. At present, seven out of eight patients are disease free. Overall toxicity profile was good; no severe acute or late genitourinary or gastrointestinal events were recorded. Multiple RT courses with high precision technology and image guidance can be proposed as a possible salvage therapy for locally recurrent, low-burden PCa recurrence in adequately selected patients. Deeper understanding of radiobiological effects of hypofractionation and larger series of patients are warranted to fully evaluate the applicability of multiple RT courses in the setting of locally recurrent PCa.
\end{abstract}

Key words: prostate cancer, re-irradiation, stereotactic radiotherapy, focal therapies, androgen deprivation therapy free interval

Other than skin cancer, prostate cancer $(\mathrm{PCa})$ is the most common cancer in men, accounting for 449.761 new cancers and 107.315 of estimated cancer deaths in Europe in 2018 [1]. For more than two decades, whole-gland external beam radiation therapy (EBRT) has been considered a mainstay in the treatment of localized PCa. Technological advances (e.g. Intensity modulated radiation therapy, IMRT, and Imageguided radiation therapy, IGRT) allowed for a progressive increase in prescribed and delivered radiation doses and opened doors to hypofractionation, which is proving to be both safe and effective [2]. Notably, recently published 10 -year outcomes from the randomized Prostate Testing for
Cancer and Treatment (ProtecT) trial showed that surgery and EBRT offer the same tumor outcome in localized low and intermediate-risk PCa [3].

Despite these diagnostic and therapeutic efforts, the rate of biochemical failure after primary course $\mathrm{RT} \pm$ androgen deprivation therapy (ADT) is still not negligible, and ranges between 22 and $69 \%$ in different patient series $[4,5]$. According to the National Comprehensive Cancer Network (NCCN) guidelines, re-staging at biochemical failure should include prostate magnetic resonance (MRI) and complete bone scan, while abdominopelvic computed tomography (CT) or MRI, C-11 choline positive-emission tomography 
(PET) and trans-rectal ultrasound (TRUS) are considered optional. In case a diagnosis of intraprostatic recurrence is made, local treatment should be evaluated. A decisional framework for patient stratification has been provided and includes: original clinical stage $\mathrm{T} 1-\mathrm{T} 2, \mathrm{Nx}$ or N0; PSA at recurrence $<10 \mathrm{ng} / \mathrm{ml}$ and life expectancy $>10$ years [6].

Consensus regarding the optimal management of intraprostatic relapse after radical treatment is still lacking. Treatment options include ADT or focal therapy such as salvage prostatectomy, high-intensity focused ultrasound (HIFU), cryotherapy, brachytherapy and re-EBRT [7]. Notably, all these data suggest that salvage local approach might defer systemic therapy in a good proportion of patients.

As a proof of concept of the dosimetric feasibility and clinical applicability of re-EBRT in PCa patients, here we present the oncological outcomes and toxicity profiles of series of eight consecutive patients treated at a comprehensive cancer center following local failure.

\section{Patients and methods}

Study design. This retrospective study is part of the research regarding clinical and dosimetric aspects of IGRT for PCa notified to the Ethical Committee of the BLINDED (notification Nr: 79). All patients gave written consent to re-treatment and to the anonymous use of clinical data for scientific and/or educational purposes.

The inclusion criteria were as follows: 1) low-burden local recurrence of PCa after primary EBRT, BRT or salvage post-prostatectomy radiotherapy (RT), 2) two or more RT courses at the BLINDED between May 2013 and September 2017 , 3) availability of previous RT treatment plans, 4) absence of either regional or distant disease at re-staging, 5) no moderate or severe genitourinary (GU) or gastro-intestinal (GI) toxicity from previous RT courses per Radiation Therapy Oncology Group (RTOG)/European Organization for Research and Treatment of Cancer (EORTC) criteria $[8], 6)$ written informed consent for radiation treatment, 7) written informed consent for use of completely anonymized clinical and imaging data for research and educational purposes. No other local salvage treatment for the recurrent PCa was permitted.

All cases were presented during the institutional weekly Uro-Oncology multidisciplinary team meeting for discussion. Following treatment, patients were reviewed every 6 months for biochemical control and RT-induced normal tissue effects. A shorter follow-up time was applied whenever needed according to best clinical practice. PSA was tested every 3 months. Biochemical failure was diagnosed by a radiation oncologist during follow-up visits and assessed according to 2006 Phoenix definition [6, 9]. Clinical recurrence was established by multiparametric MRI (mpMRI) and/or PET/CT scan.

Clinical and radiological data of the primary and recurrent tumor were retrospectively collected from electronic medical records. Treatment plans were retrieved for each patient using iPlan Net 3.0.0 (Brainlab, Munich, Germany) and Cyberknife MultiPlan System for treatment planning (Accuray, Sunnyvale, California, USA).

Radiotherapy procedures. Previous treatment plans had been evaluated for each patient. CT simulation and RT sessions were performed with full urinary bladder and empty rectum, according to oral and written instructions handed over during the first visit (water intake of $500 \mathrm{ml}$ 30 minutes before CT simulation and treatment; enema the day before CT simulation and low-fiber diet during radiation treatment).

In the third RT setting, mpMRI was used for target delineation for 5 patients (case 1, 3-6), C-11 choline-PET was employed for one patient (case 2); while mpMRI was the technique of choice for treatment planning for the fourth RT course (case 1 and case 3). Gross tumor volume (GTV) included exclusively the site of clinical relapse (focal RT/ partial prostate irradiation); no margin for subclinical disease was given. Every patient underwent IGRT prior to irradiation. Indication to treatment with Cyberknife ${ }^{\oplus}$ was given only to patients who had had fiducial markers implanted at the time of the first RT course. Biodegradable spacers, such as hydrogel were not used in our cohort.

For patients treated with $\mathrm{VERO}^{\circ}$, planning target volume (PTV) margins were obtained expanding the GTV of $5 \mathrm{~mm}$ except for the posterior expansion of GTV, which was $3 \mathrm{~mm}$. Conversely, a $3 \mathrm{~mm}$ expansion was given to all margins but the posterior, which received an expansion of $1 \mathrm{~mm}$ in all cases treated with Cyberknife ${ }^{\bullet}$. Delineation of organs at risk included rectum, urinary bladder, cauda equina, peritoneal cavity, femoral heads, penile bulb, penis, testis and femoral heads. Dosimetric constraints for re-EBRT were based on a previous experience reported by Jereczek-Fossa et al. [17], namely: urinary bladder dose to $30 \%$ of volume $<10.58 \mathrm{~Gy}$, rectum dose to $30 \%$ of volume $<13.8 \mathrm{~Gy}$ and penile bulb volume receiving $29 \mathrm{~Gy}<50 \%$.

\section{Results}

Between May 2013 and September 2017 eight patients received three RT courses at the BLINDED for isolated intraprostatic or local relapse of PCa (two salvage re-EBRT courses); two of them received four RT courses (three salvage re-EBRT courses).

Four patients had received both previous RT courses at our Institution, while four had had the primary treatment at another radiation facility. Two patients had undergone radical prostatectomy as primary treatment of PCa. ADT was not prescribed due to severe cardiologic comorbidities (two patients) or non-compliance (two patients). One patient (case 5) underwent subcutaneous bilateral mastectomy for severe gynecomastia secondary to treatment with Bicalutamide. None of the patients received concomitant ADT at the time of re-irradiation. 
Mean age at the third RT course was 72 (SD: 8.8), patients who received the forth RT were 78 (case 1) and 66 (case 3) years old. All patients had a good performance status according to Karnofsky and Eastern Cooperative Oncology Group (ECOG) scores. In the non-surgical scenario (six patients), mean PSA at the time of first and second relapse was 5.2 (SD: 3.7) and 5.3 (SD: 4.4) ng/ml, respectively. Median biochemical progression free interval after first and second RT-course were 74 (IQR: 59.3-133.6) months and 33 (IQR: 20.8-53.1) months, respectively. Taking into consideration all RT courses in all patients, the median interval between the first and second RT was 88 (IQR: 67.8-140.5) months, whereas the interval between the second and third
RT was 37.5 (IQR 26.3-58.1) months. In the two cases with four RT courses, the interval between the third and fourth RT was 32 months for patient 1 and 57 months for patient 3 . A summary of radiation treatments characteristics by patient is provided in Table 1.

Median follow-up time from diagnosis was 168.5 (IQR: 144.2-203.1) months for the whole cohort. Median followup time from the third RT was 12 (IQR: 3.1-42.5) months; follow-up time from the forth RT course was 17 and 6 months for patient 1 and patient 3 , respectively.

Biochemical and clinical response has been registered in all patients. At present, seven out of eight patients are free of both biochemical and clinical disease. Patient 1 was

Table 1. Radiation treatment characteristics by patient.

\begin{tabular}{|c|c|c|c|c|}
\hline Date of treatment & Treated Volume & Technique & Total Dose; Dose/fraction & $\begin{array}{c}\text { BED } \\
(\alpha / \beta=1.5 \mathrm{~Gy})\end{array}$ \\
\hline \multicolumn{5}{|c|}{ Patient 1- NCCN 2017 Initial Risk Group: Intermediate } \\
\hline $\begin{array}{l}\text { Sept-Nov } 2005 \\
(67 \text { ys) }\end{array}$ & Prostate $+1 / 3$ Seminal Vesicles & 3D-CRT & 76 Gy, 2 Gy/fract. & $177.3 \mathrm{~Gy}$ \\
\hline $\begin{array}{l}\text { Feb } 2010 \\
(72 \text { ys })\end{array}$ & $\begin{array}{l}\text { Prostate } \\
\left(\text { GTV } 48.81 \mathrm{~cm}^{3}\right)\end{array}$ & SBRT CyberKnife & $30 \mathrm{~Gy}, 6 \mathrm{~Gy} /$ fract. & $150.0 \mathrm{~Gy}$ \\
\hline $\begin{array}{l}\text { Sept-Oct } 2013 \\
\text { (75 ys) }\end{array}$ & $\begin{array}{l}\text { Intraprostatic lesion, apex } \\
\left(\text { GTV } 25.18 \mathrm{~cm}^{3}\right)\end{array}$ & SBRT CyberKnife ${ }^{\oplus}$ & 25 Gy, 5 Gy/fract. & $108.3 \mathrm{~Gy}$ \\
\hline $\begin{array}{l}\text { May } 2016 \\
(78 \mathrm{ys})\end{array}$ & $\begin{array}{l}\text { Intraprostatic lesion, apex } \\
\left(\mathrm{GTV} 1.0 \mathrm{~cm}^{3}\right)\end{array}$ & SBRT CyberKnife ${ }^{\oplus}$ & 25 Gy, 5 Gy/fract. & $108.3 \mathrm{~Gy}$ \\
\hline \multicolumn{5}{|c|}{ Patient 2- NCCN 2017 Initial Risk Group: Low } \\
\hline $\begin{array}{l}\text { Jan-March } 2005 \\
(65 \text { ys })\end{array}$ & Prostate+ $1 / 3$ Seminal Vesicles & 3D-CRT & $\begin{array}{c}76 \text { Gy, } \\
2 \text { Gy/fract. }\end{array}$ & $177.3 \mathrm{~Gy}$ \\
\hline $\begin{array}{l}\text { March } 2012 \\
(72 \text { ys })\end{array}$ & $\begin{array}{l}\text { Prostate } \\
\left(\text { GTV } 25.06 \mathrm{~cm}^{3}\right)\end{array}$ & SBRT CyberKnife & $\begin{array}{l}25 \mathrm{~Gy} \\
5 \text { Gy/fract. }\end{array}$ & $108.3 \mathrm{~Gy}$ \\
\hline $\begin{array}{l}\text { Sept } 2015 \\
(76 \text { ys) }\end{array}$ & $\begin{array}{l}\text { Intraprostatic lesion, left lobe } \\
\left(\text { GTV } 3.1 \mathrm{~cm}^{3}\right)\end{array}$ & SBRT CyberKnife ${ }^{\oplus}$ & 30 Gy, 6 Gy/fract. & $150.0 \mathrm{~Gy}$ \\
\hline \multicolumn{5}{|c|}{ Patient 3- NCCN 2017 Initial Risk Group: Intermediate } \\
\hline $\begin{array}{l}\text { Feb-March } 2003 \\
(52 \text { ys) }\end{array}$ & Prostate & 3D-CRT + Brachytherapy & $\begin{array}{l}50 \text { Gy, } 2 \text { Gy/fract. + } \\
100 \text { Gy I-125 seeds }\end{array}$ & N.E. \\
\hline $\begin{array}{l}\text { Apr-May } 2010 \\
(59 \text { ys })\end{array}$ & $\begin{array}{l}\text { Prostate } \\
\left(\text { GTV } 24.19 \mathrm{~cm}^{3}\right)\end{array}$ & 3D-CRT & 30 Gy, 6 Gy/fract. & 150.0 Gy \\
\hline $\begin{array}{l}\text { Jul } 2012 \\
(61 \mathrm{ys})\end{array}$ & $\begin{array}{l}\text { Peri-prostatic node } \\
\left(\text { GTV } 12.98 \mathrm{~cm}^{3}\right)\end{array}$ & $\begin{array}{l}\text { IMRT } \\
\text { VERO }^{\circ}\end{array}$ & 32 Gy, 4 Gy/fract. & $117.33 \mathrm{~Gy}$ \\
\hline $\begin{array}{l}\text { Feb } 2017 \\
(66 \text { ys })\end{array}$ & $\begin{array}{l}\text { Seminal vesicles, proximal portion } \\
\left(\text { GTV } 9.98 \mathrm{~cm}^{3}\right)\end{array}$ & $\begin{array}{l}\text { IMRT } \\
\text { VERO }^{\circ}\end{array}$ & 25 Gy, 5 Gy/fract. & $108.3 \mathrm{~Gy}$ \\
\hline \multicolumn{5}{|c|}{ Patient 4- NCCN 2017 Initial Risk Group: High } \\
\hline $\begin{array}{l}\text { Jan-March } 2007 \\
\text { (55 ys) }\end{array}$ & $\begin{array}{l}\text { True pelvis, prostate and seminal } \\
\text { vesicles boost }\end{array}$ & 3D-CRT & 76 Gy, 2 Gy/fract. & $177.3 \mathrm{~Gy}$ \\
\hline $\begin{array}{l}\text { Apr } 2014 \\
(62 \text { ys })\end{array}$ & $\begin{array}{l}\text { Left apex and right peripheral zone } \\
\left(\mathrm{GTV} 1+\mathrm{GTV} 26.415 \mathrm{~cm}^{3}\right)\end{array}$ & $\begin{array}{l}\text { IMRT } \\
\text { VERO }^{\circ}\end{array}$ & 30 Gy, 10 Gy/fract. & 90.0 Gy \\
\hline $\begin{array}{l}\text { June } 2016 \\
(64 \text { ys })\end{array}$ & $\begin{array}{l}\text { Right prostate lobe } \\
\left(\text { GTV } 20.0 \mathrm{~cm}^{3}\right)\end{array}$ & $\begin{array}{l}\text { IMRT }^{-} \\
\text {VERO }^{\circ}\end{array}$ & 25 Gy, 5 Gy/fract. & $108.3 \mathrm{~Gy}$ \\
\hline \multicolumn{5}{|c|}{ Patient 5- NCCN 2017 Initial Risk Group: High } \\
\hline $\begin{array}{l}\text { Oct } 2003 \\
(56 \text { ys })\end{array}$ & $\begin{array}{l}\text { True pelvis, prostate and seminal } \\
\text { vesicles boost }\end{array}$ & 3D-CRT & 78.4 Gy, 2 Gy/fract. & $182.93 \mathrm{~Gy}$ \\
\hline $\begin{array}{l}\text { Jun-Jul } 2015 \\
(68 \text { ys })\end{array}$ & $\begin{array}{l}\text { Prostate } \\
\left(\text { GTV } 30.65 \mathrm{~cm}^{3}\right)\end{array}$ & $\begin{array}{l}\text { IMRT } \\
\text { VERO }^{\circ}\end{array}$ & 30 Gy, 6 Gy/fract & $150.0 \mathrm{~Gy}$ \\
\hline $\begin{array}{l}\text { May } 2017 \\
(70 \text { ys })\end{array}$ & $\begin{array}{l}\text { Intraprostatic lesion, } \\
\text { left lobe }\left(\mathrm{GTV} 4.27 \mathrm{~cm}^{3}\right)\end{array}$ & $\begin{array}{c}\text { IMRT } \\
\text { VERO }^{\circ}\end{array}$ & $25 \mathrm{~Gy}, 5 \mathrm{~Gy} /$ fract & $108.3 \mathrm{~Gy}$ \\
\hline
\end{tabular}

Legend: BED: Biologically Effective Dose; 3D-CRT: Three Dimensional-Conformal Radiation Therapy; GTV: Gross Tumor Volume; IMRT: Intensity Modulated Radiotherapy; NCCN: National Comprehensive Cancer Network ${ }^{\circledR}$ SBRT: Stereotactic Body Radiation Therapy; fract: fraction; ys: years; NE: Not Evaluable. 
Table 1. Continued

\begin{tabular}{|c|c|c|c|c|}
\hline Date of treatment & Treated Volume & Technique & Total Dose; Dose/fraction & $\begin{array}{c}\text { BED } \\
(\alpha / \beta=1.5 \mathrm{~Gy})\end{array}$ \\
\hline \multicolumn{5}{|c|}{ Patient 6- NCCN 2017 Initial Risk Group: High } \\
\hline $\begin{array}{l}\text { Jul- Sept } 2000 \\
\text { (64 years) }\end{array}$ & Prostate & 3D-CRT & 70 Gy, 2 Gy/fract. & $163.33 \mathrm{~Gy}$ \\
\hline $\begin{array}{l}\text { Jul } 2012 \\
\text { (76 years) }\end{array}$ & $\begin{array}{l}\text { Partial prostate irradiation (Right lobe) } \\
\text { (GTV } 25.51 \mathrm{~cm}^{3} \text { ) }\end{array}$ & $\begin{array}{l}\text { IMRT } \\
\text { VERO }^{\circ}\end{array}$ & 25 Gy, 5 Gy/fract & $108.3 \mathrm{~Gy}$ \\
\hline $\begin{array}{l}\text { Sept } 2017 \\
\text { (81 years) }\end{array}$ & $\begin{array}{l}\text { Right prostate apex } \\
\left(\text { GTV } 2.66 \mathrm{~cm}^{3}\right)\end{array}$ & $\begin{array}{l}\text { IMRT } \\
\text { VERO }^{\circ}\end{array}$ & $30 \mathrm{~Gy}, 6 \mathrm{~Gy} /$ fract & $150.0 \mathrm{~Gy}$ \\
\hline \multicolumn{5}{|c|}{ Patient 7- NCCN 2017 Initial Risk Group: Intermediate } \\
\hline $\begin{array}{l}\text { May-Jun } 2009 \\
(56 \text { ys })\end{array}$ & Prostate bed & 3D-CRT & 70 Gy, 2 Gy/fract. & $163.33 \mathrm{~Gy}$ \\
\hline $\begin{array}{l}\text { Jun } 2014 \\
(61 \mathrm{ys})\end{array}$ & $\begin{array}{l}\text { Left-posterior para-uretheral region } \\
\left(\text { GTV } 7.31 \mathrm{~cm}^{3}\right)\end{array}$ & $\begin{array}{l}\text { IMRT } \\
\text { VERO }^{\circ}\end{array}$ & 25 Gy, 5 Gy/fract. & $108.3 \mathrm{~Gy}$ \\
\hline $\begin{array}{l}\text { February } 2017 \\
(63 \mathrm{ys})\end{array}$ & $\begin{array}{l}\text { Ureterovesical junction, antero-lateral por- } \\
\text { tion, left }\left(\mathrm{GTV} 3.71 \mathrm{~cm}^{3}\right)\end{array}$ & $\begin{array}{l}\text { IMRT } \\
\text { VERO }^{\circ}\end{array}$ & 25 Gy, 5 Gy/fract. & $108.3 \mathrm{~Gy}$ \\
\hline \multicolumn{5}{|c|}{ Patient 8- NCCN 2017 Initial Risk Group: High } \\
\hline $\begin{array}{l}\text { Jun } 2006 \\
(74 \mathrm{ys})\end{array}$ & Prostate bed & 3D-CRT & 76 Gy, 2 Gy/fract. & $177.3 \mathrm{~Gy}$ \\
\hline $\begin{array}{l}\text { May } 2010 \\
(78 \text { ys })\end{array}$ & Prostate bed, paramedian region & $\begin{array}{l}\text { IMRT } \\
\text { VERO }^{\circ}\end{array}$ & 25 Gy, 5 Gy/fract. & $108.3 \mathrm{~Gy}$ \\
\hline $\begin{array}{l}\text { Jul } 2017 \\
(85 \mathrm{ys})\end{array}$ & $\begin{array}{l}\text { Prostate bed, left region } \\
\left(\text { GTV } 8.80 \mathrm{~cm}^{3}\right)\end{array}$ & $\begin{array}{l}\text { IMRT } \\
\text { VERO }^{\circ}\end{array}$ & $30 \mathrm{~Gy}, 6 \mathrm{~Gy} / \mathrm{fract}$ & $150.0 \mathrm{~Gy}$ \\
\hline
\end{tabular}

Legend: BED: Biologically Effective Dose; 3D-CRT: Three Dimensional-Conformal Radiation Therapy; GTV: Gross Tumor Volume; IMRT: Intensity Modulated Radiotherapy; NCCN: National Comprehensive Cancer Network ${ }^{\circledR}$ SBRT: Stereotactic Body Radiation Therapy; fract: fraction; ys: years; NE: Not Evaluable.

recently diagnosed with local relapse into the right seminal vesicle and has been candidate to short-course ADT. Indication to systemic therapy was tailored to risk features of the recurrence and patient preference. The choice of short-term course was given because of relative cardiological contraindication to ADT.

In all patients, re-EBRT granted avoidance (patient 1) or at least deferral of ADT. Specifically, patient 2 and patient 3 experienced a single short course ADT since PCa was first diagnosed, reaching a current ADT-free survival of 145 and 86 months, respectively. Also patients with high-risk PCa and low-burden, intraprostatic recurrence could benefit from re-EBRT (cases 4-6). In this case, a local approach may allow for intermittent instead of continuous ADT with an expected positive impact on quality of life. The two surgical patients in our series (patient 7 and 8) showed good tolerance to multiple RT courses in the prostate bed, and no GU or GI complication.

No acute or late moderate to severe GU or GI toxicities have been diagnosed in those cases. Patient 5 reported lateonset GU toxicity which was graded as mild and successfully treated with medical therapy according to best clinical practice.

\section{Discussion}

To the best of our knowledge this is the first case series on multiple RT courses for limited volume intraprostatic or local PCa recurrence. Our experience shows that such approach, combined with high-precision RT modalities, is safe and may offer a long-term progression free survival (median to time to relapse: 40 months) thus allowing to defer systemic therapies (ADT) and related toxicities.

Although the range of possible local salvage options is wide, the most commonly prescribed treatment is still ADT. Data collected in 2008 from the Cancer of the Prostate Strategic Urological Research Endeavor (CaPSURE) database [10] showed that up to $93 \%$ patients underwent ADT after intraprostatic relapse, while only a small proportion was considered a candidate for local treatment. A similar observation was replied more recently by Tran et al. [11] in a population of 257 patients from the British Columbia Tumour Registry, irradiated between 1999 and 2000 for PCa. Only 2\% of these patients received local salvage, which was radical prostatectomy in 3 cases and brachytherapy in 2 cases, while the most common approaches were observation and ADT (126 and 119 patients, respectively). This is an unusual scenario in oncology, since in any other tumor site the isolated primary tumor low-volume local recurrence is treated, whenever possible, by radical local approach (e.g.: breast and head and neck cancers, sarcomas etc.) [7]. The literature shows an underutilization of local strategies in relapsing PCa, as well as the need for more robust evidence and enhanced collaboration between specialties to optimize care pathways. In the field of radiation oncology, promising results from stereotactic re-EBRT have recently been published by Fuller et al. [12], Janoray et al. [13], Detti el al. [14], Zerini et al. [15], Vavassori et al. [16] and Jereczek-Fossa et al. [17]. 
In the setting of primary treatment for $\mathrm{PCa}$, focal therapies have come to attention as a suitable option in adequately selected patients [18-20]. Actually, such a limited approach has been introduced in the salvage therapy and indeed, all our patients underwent focal re-treatment in case of second or third local recurrence. In non-surgical patients, the whole prostate was re-treated after the first clinical recurrence. The treated volume decreased with subsequent RT courses in all but one patient in our series. The issue of the treated volume in the salvage scenario has not been established although it may be correlated, together with the dose and technique, with re-EBRT toxicity $[11-17,21]$.

Focal approach aims to the ablation of the index lesion. Any energy could be used, provided that the capability of the ablative modality and the characteristics of the disease are taken into account when planning the treatment. Though, a standardized strategy has not been defined [22]. This has led to limited homogeneity of treatment indications between centers, and subsequent underutilization of potentially curative options in intraprostatic and local recurrences of PCa. Recently, the members of the URO-Group Européen de Curiethérapie (GEC) - European SocieTy for Radiotherapy and Oncology (ESTRO) have published a consensus study to explore expert opinion on the management of salvage prostate brachytherapy [23]. So far, such consensus for re-EBRT is missing. A recent work by Mbeutcha at al. has shown the feasibility of high-dose-rate brachytherapy on whole prostate gland and focal (SBRT) using CyberKnife ${ }^{\circledast}$ after primary EBRT. Interestingly no significant difference was found in the toxicity outcome between the two RT modalities [24].

Although we recognize that follow-up time after the third RT course is not mature for comprehensive evaluation of oncological and toxicity outcomes, as far as we have documented through systematic clinical assessment, tolerance to multiple RT courses for limited intra-prostatic/local recurrence was good. Therefore, our results suggest that third, or even forth EBRT course with high-precision technology could represent a safe alternative to radical salvage surgery or systemic therapies in carefully selected patients. Eligible candidates should satisfy NCCN recommendations for re-treatment (original clinical stage T1-T2, Nx or N0; PSA at recurrence $<10 \mathrm{ng} / \mathrm{ml}$ and life expectancy $>10$ years), while biopsy should be considered especially when imaging does not provide an unequivocal evidence of recurrence. Clinical status should also be taken into account and accurate screening for late GU or GI effects is strongly recommended. Considering patient selection for multiple RT courses, cardiologic comorbidities (coronary disease, diabetes mellitus, obesity, hyperlipemia, metabolic syndrome) could be regarded as additional criteria, as this subgroup of patients could benefit from a minimally-invasive therapy with no impact on pre-existing clinical conditions. In this setting, RT could be regarded as a strategy to avoid, or at least delay the prescription of ADT, whose cardiologic side effects have nowadays been recognized and extensively reviewed [25-27].
We are aware of the limitations of our report, first of all the low number of cases, the heterogeneity of the initial and salvage therapies (dose, fractionation, approach including brachytherapy, 3-dimensional Conformal RT, 3D-CRT, IMRT etc.) and the lack of histological confirmation for all intraprostatic recurrences. Specifically, prostate biopsy was performed in four patients. This strategy was extensively discussed both with the patients and within the multidisciplinary tumor board. It has been considered that in case of univocal findings in mpMRI and/or choline-PET showing intraprostatic relapse together with biochemical relapse, local therapy was suitable. Notably, prostate biopsy has been associated with up to $2.8 \%$ of complications, so that the risks may outweigh the potential benefits of the procedure [28].

Nevertheless, local control seems suboptimal in our experience, and that could suggest some room for dose escalation in order to overcome possible mechanisms of radioresistance. In our work, we assumed a low $\alpha / \beta$ for $\mathrm{PCa}$ (1.5 Gy), in agreement with recent radiobiological findings $[29,30]$. If this assumption is true, dose escalation might be achieved by the delivery of larger dose/fraction without a substantial increase in overall treatment time. The role of short ADT in the setting of salvage RT has recently been investigated $[31,32]$, so this approach should be re-considered together with dose escalation in order to increase local control in recurrent disease. Interestingly, the GEC-ESTRO consensus discourages the use of ADT in the salvage prostate brachytherapy setting [23]. Moreover, a recent report by Fanetti et al. [33] has demonstrated no additional benefit from the addition of ADT to SBRT in a homogenous cohort of oligometastatic hormone-naïve PCa patients in terms of both biochemical and clinical progression-free survival, prostate-specific survival and local control.

Technology innovation (e.g. IGRT, MRI-based treatment planning) is crucial to achieve dose escalation, as it allows to minimize treatment volumes without increasing both the risk of geographical missing and toxicity of organs at risk. Moreover, the application in routine clinical practice of biodegradable devices such as hydrogel spacers may further contribute to the realization of optimized dose distributions even in the setting of stereotactic multiple re-EBRT [34].

So far, trials investigating clinical and toxicity outcomes of moderate hypofractionation have shown similar results to those of conventionally fractionated regimens, while extreme hypofractionated schedules need longer follow-up data to be confirmed as a standard treatment option for PCa $[35,36]$. Ultimately, multiple RT courses with high precision technology may be regarded as a possible treatment option for intraprostatic second relapse of PCa in adequately selected patients. Results from studies on hypofractionation and local therapies together with a deeper understanding in radiobiology are warranted to fully evaluate feasibility of this approach in larger series of patients. 
Acknowledgements: This study was partially supported by Associazione Italiana per la Ricerca sul Cancro (AIRC), project IG14300: "Carbon ions boost followed by pelvic photon intensity radiotherapy for high-risk prostate cancer", registered at ClinicalTrials.gov (NCT02672449), approved by IEO R86/14- IEO 98 (fellowships to P. Romanelli and P. de Marco).

\section{References}

[1] Ferlay J, Colombet M, Soerjomataram I, Dyba T, Randi G et al. Cancer incidence and mortality patterns in Europe: Estimates for 40 countries and 25 major cancers in 2018. Eur J Cancer 2018; 103: 356-387. https://doi.org/10.1016/j. ejca.2018.07.005

[2] ZAORSKY NG, KEITH SW, SHAIKH T, NGUYEN PL, HORWITZ EM et al. Impact of Radiation Therapy Dose Escalation on Prostate Cancer Outcomes and Toxicities. Am J Clin Oncol 2018; 41: 409-415. https://doi.org/10.1097/ COC. 0000000000000285

[3] HAMDY FC, DONOVAN JL, LANE JA, MASON M, METCALFE C et al. 10-Year Outcomes after Monitoring, Surgery, or Radiotherapy for Localized Prostate Cancer. N Engl J Med 2016; 375: 1415-1424. https://doi.org/10.1056/NEJMoa1606220

[4] NEPPL-HUBER C, ZAPPA M, COEBERGH JW, RAPITI E, RACHTAN J et al. Changes in incidence, survival and mortality of prostate cancer in Europe and the United States in the PSA era: additional diagnoses and avoided deaths. Ann Oncol 2012;23:1325-1334.https://doi.org/10.1093/annonc/mdr414

[5] KUBAN DA, THAMES HD, LEVY LB. Radiation for prostate cancer: use of biochemical failure as an endpoint following radiotherapy. World J Urol 2003; 21: 253-264. https:// doi.org/10.1007/s00345-003-0361-0

[6] National Comprehensive Cancer Network. Prostate Cancer (Version 4.2018). https://www.nccn.org/professionals/physician_gls/pdf/prostate.pdf. Accessed October 30, 2018

[7] ALONGI F, DE BARI B, CAMPOSTRINI F, ARCANGELI $S$, MATEI DV et al. Salvage therapy of intraprostatic failure after radical external-beam radiotherapy for prostate cancer: a review. Crit Rev Oncol Hematol 2013; 88: 550-563. https:// doi.org/10.1016/j.critrevonc.2013.07.009

[8] TROTTI A, BYHARDT R, STETZ J, GWEDE C, CORN B et al. Common toxicity criteria: version 2.0. An improved reference for grading the acute effects of cancer treatment: impact on radiotherapy. Int. J. Radiation Oncology Biol Phys 2000; 47: 13-47. https://doi.org/10.1016/S0360-3016(99)00559-3

[9] ROACH M 3RD, HANKS G, THAMES H JR, SCHELLHAMMER P, SHIPLEY WU et al. Defining biochemical failure following radiotherapy with or without hormonal therapy in men with clinically localized prostate cancer: recommendations of the RTOG-ASTRO Phoenix Consensus Conference. Int J Radiat Oncol Biol Phys 2006; 65: 965-974. https://doi.org/10.1016/j.ijrobp.2006.04.029

[10] AGARWAL PK, SADETSKY N, KONETY BR, RESNICK MI, CARROLL PR et al. Treatment failure after primary and salvage therapy for prostate cancer: likelihood, patterns of care, and outcomes. Cancer 2008; 112: 307-314. https://doi. org/10.1002/cncr.23161
[11] TRAN H, KWOK J, PICKLES T, TYLDESLEY S, BLACK PC. Underutilization of local salvage therapy after radiation therapy for prostate cancer. Urol Oncol 2014; 32: 701-706. https://doi.org/10.1016/j.urolonc.2013.12.014

[12] FULLER DB, WURZER J, SHIRAZI R, BRIDGE SS, LAW J et al. High-dose-rate stereotactic body radiation therapy for postradiation therapy locally recurrent prostatic carcinoma: Preliminary prostate-specific antigen response, disease-free survival, and toxicity assessment. Pract Radiat Oncol 2015; 5: e615-623. https://doi.org/10.1016/j.prro.2015.04.009

[13] JANORAY G, REYNAUD-BOUGNOUX A, RUFFIERLOUBIERE A, BERNADOU G, POINTREAU Y et al., Stereotactic body re-irradiation therapy for locally recurrent prostate cancer after external-beam radiation therapy: Initial report. Cancer Radiother 2016; 20: 275-281. https://doi. org/10.1016/j.canrad.2016.03.005

[14] DETTI B, BONOMO P, MASI L, DORO R, CIPRESSI S et al. CyberKnife stereotactic radiotherapy for isolated recurrence in the prostatic bed. World J Urol 2016; 34: 311-317. https://doi.org/10.1007/s00345-015-1613-5

[15] ZERINI D, JERECZEK-FOSSA BA, FODOR C, BAZZANI F, MAUCIERI A et al. Salvage image-guided intensity modulated or stereotactic body reirradiation of local recurrence of prostate cancer. Br J Radiol 201; 88: 20150197. https://doi. org/10.1259/bjr.20150197

[16] VAVASSORI A, JERECZEK-FOSSA BA, BELTRAMO G, DE CICCO L, FARISELLI L et al. Image-guided robotic radiosurgery as salvage therapy for locally recurrent prostate cancer after external beam irradiation: retrospective feasibility study on six cases. Tumori 2010; 96: 71-75.

[17] JERECZEK-FOSSA BA, BELTRAMO G, FARISELLI L, FODOR C, SANTORO L et al. Robotic image-guided stereotactic radiotherapy, for isolated recurrent primary, lymph node or metastatic prostate cancer. Int J Radiat Oncol Biol Phys 2012; 82: 889-897. https://doi.org/10.1016/j. ijrobp.2010.11.031

[18] JERECZEK-FOSSA BA, CIARDO D, PETRALIA G, BELLOMI M, DE BARI B et al. Primary focal prostate radiotherapy: Do all patients really need whole-prostate irradiation? Crit Rev Oncol Hematol 2016; 105: 100-111. https:// doi.org/10.1016/j.critrevonc.2016.06.010

[19] KLOTZ L. Active surveillance and focal therapy for lowintermediate risk prostate cancer. Transl Androl Urol 2015; 4: 342-354. https://doi.org/10.3978/j.issn.22234683.2015.06.03

[20] DONALDSON IA, ALONZI R, BARRATT D, BARRET E, BERGE V et al. Focal therapy: patients, interventions, and outcomes--a report from a consensus meeting. Eur Urol 2015; 67: 771-777. https://doi.org/10.1016/j.eururo.2014.09.018

[21] ZILLI T, BENZ E, DIPASQUALE G, ROUZAUD M, MIRALBELL R. Reirradiation of Prostate Cancer Local Failures After Previous Curative Radiation Therapy: Long-Term Outcome and Tolerance. Int J Radiat Oncol Biol Phys 2016; 96: 318-322. https://doi.org/10.1016/j.ijrobp.2016.05.024

[22] PERERA M, KRISHNANANTHAN N, LINDNER U, LAWRENTSCHUK N. An update on focal therapy for prostate cancer. Nat Rev Urol 2016; 13: 641-653. https://doi. org/10.1038/nrurol.2016.177 
[23] KALJOUW E, PIETERS BR, KOVACS G, HOSKIN PJ. A Delphi consensus study on salvage brachytherapy for prostate cancer relapse after radiotherapy, a Uro-GEC study. Radiother Oncol 2016; 118: 122-130. https://doi.org/10.1016/j. radonc.2015.10.021

[24] MBEUTCHA A, CHAUVEINC L, BONDIAU PY, CHAND ME, DURAND $M$ et al. Salvage prostate re-irradiation using high-dose-rate brachytherapy or focal stereotactic body radiotherapy for local recurrence after definitive radiation therapy. Radiat Oncol 2017; 12: 49. https://doi.org/10.1186/ s13014-017-0789-9

[25] JIN C, FAN Y, MENG Y, SHEN C, WANG Y et al. A metaanalysis of cardiovascular events in intermittent androgendeprivation therapy versus continuous androgen-deprivation therapy for prostate cancer patients. Prostate Cancer Prostatic Dis 2016; 19: 333-339. https://doi.org/10.1038/ pcan.2016.35

[26] CORNFORD P, BELLMUNT J, BOLLA M, BRIERS E, DE SANTIS $M$ et al. EAU-ESTRO-SIOG Guidelines on Prostate Cancer. Part II: Treatment of Relapsing, Metastatic, and Castration-Resistant Prostate Cancer. Eur Urol 2017; 71: 630-642. https://doi.org/10.1016/j.eururo.2016.08.002

[27] IACOVELLI R, VERRI E, COSSU ROCCA M, AURILIO G, CULLURA D et al. The incidence and relative risk of cardiovascular toxicity in patients treated with new hormonal agents for castration-resistant prostate cancer. Eur J Cancer 2015; 51: 1970-1977. https://doi.org/10.1016/j. ejca.2015.06.106

[28] BRUYERE F, MALAVAUD S, BERTRAND P, DECOCK A, CARIOU G et al. Prosbiotate: a multicenter, prospective analysis of infectious complications after prostate biopsy. J Urol 2015; 193: 145-150. https://doi.org/10.1016/j. juro.2014.07.086
[29] NAHUM AE. The radiobiology of hypofractionation. Clin Oncol (R Coll Radiol) 2015; 27: 260-269. https://doi. org/10.1016/j.clon.2015.02.001

[30] BROWN JM, CARLSON DJ, BRENNER DJ. The tumor radiobiology of SRS and SBRT: are more than the 5 Rs involved? Int J Radiat Oncol Biol Phys 2014; 88: 254-262. https://doi.org/10.1016/j.ijrobp.2013.07.022

[31] SHIPLEY WU, SEIFERHELD W, LUKKA HR, MAJOR PP, HENEY NM et al. Radiation with or without Antiandrogen Therapy in Recurrent Prostate Cancer. N Engl J Med 2017; 376: 417-428. https://doi.org/10.1056/NEJMoa1607529

[32] Carrie, C., et al., Salvage radiotherapy with or without shortterm hormone therapy for rising prostate-specific antigen concentration after radical prostatectomy (GETUG-AFU 16): a randomised, multicentre, open-label phase 3 trial. Lancet Oncol, 2016. 17(6): p. 747-56.

[33] FANETTI G, MARVASO G, CIARDO D, RESE A, RICOTTI R et al. Stereotactic body radiotherapy for castration-sensitive prostate cancer bone oligometastases. Med Oncol 2018; 35: 75. https://doi.org/10.1007/s12032-018-1137-0

[34] FIORENTINO A, GIAJ LEVRA N, MAZZOLA R, FERSINO S, RICCHETTI F et al. Stereotactic body radiation therapy with hydrogel spacer: a salvage reirradiation strategy for prostate cancer recurrence. Minerva Urol Nefrol 2016; 68: 464-466.

[35] ARCANGELI S, GRECO C. Hypofractionated radiotherapy for organ-confined prostate cancer: is less more? Nat Rev Urol 2016; 13: 400-408. https://doi.org/10.1038/nrurol.2016.106

[36] DE BARI B, ARCANGELI S, CIARDO D, MAZZOLA R, ALONGI $\mathrm{F}$ et al. Extreme hypofractionation for early prostate cancer: Biology meets technology. Cancer Treat Rev 2016; 50: 48-60. https://doi.org/10.1016/j.ctrv.2016.08.005 